ORIGINAL ARTICLE

\title{
The relationship between self-regulated learning strategies and students' academic performance in English course
}

HELIA NODEH ${ }^{1}$

${ }^{1}$ Master of Teaching Language, Science and Research Branch, Azad university, Tehran, Iran, Email Address: helia.nodeh@gmail.com, Orcid.org/0000-0002-4448-0929

\begin{abstract}
This study examines the relationship between self-regulated learning strategies and students' academic performance in English courses. The research method is descriptive-correlational. The statistical population includes all students of Azad University, Gorgan branch in the period 2020-2021. convenience sampling based on the Morgan table is used to select 384 people. The data collection tool is Zimmerman and Martinez-Pons SelfRegulated Learning Interview Schedule (1998), and for academic performance, the average grade in English course in two semesters was taken into account. Pearson correlation analyzes the data. The results show a significant relationship between self-regulated learning strategies and the academic performance of English course students.
\end{abstract}

Keywords: education, academic performance, learning strategy

\section{INTRODUCTION}

As a global language and an assessment tool for new scientific information in various scientific, research, and cultural fields, English language mastery is essential. Therefore, all those involved in language teaching have a severe and significant responsibility to provide the right conditions for better language learning. What needs to be considered in this regard is that many human resources are teaching English, and it costs much money to implement it, and learners spend hours learning the language. The result is not as desirable as it should be, and learners can not use it effectively in life, career, and education (Behroozi et al., 2014). Self-regulated learning strategies have subcategories as follows: behavioral self-regulation, motivational self-regulation, cognitive self-regulation, and metacognitive self-regulation (Amini, 2008). Behavioral self-regulation is to make optimal use of various resources that enhance learning. Motivational self-regulation refers to the active application of motivational strategies that enhance learning. These learners see themselves as competent, self-sufficient, and independent at all stages of learning. Learners are Cognitive and metacognitive selfregulated individuals involved in planning, organizing, selflearning, self-control, and self-assessment (Chang; quoted by Kajbaf et al., 2003).

Self-regulated learning strategies focus on how students personally control, modify, and adjust their learning process. Therefore, Academic achievement motivation and academic performance is one of the variables associated with self-regulated learning strategies. Developing self-regulation skills at a higher level of education is very important in our age where knowledge is changing rapidly. Achievement Motivation can also lead to other outcomes such as academic achievement and interest in lessons and school. Students with academic achievement motivation attribute success to their effort rather than luck or ease of homework. Failure is a temporary problem and not an accusation against their ability. Zimmerman (1999) also believes that usually, most students use self-regulated learning strategies. What distinguishes self-regulated students from others is their knowledge of how to use these strategies and their motivation to use them (Sobhaninejad, 2006). We all know that starting school is a new experience for all students, and whenever we are faced with a new situation, we are more inclined to go back to our past experiences and habits to use what we already knew. However, in most cases, our past habits may not work well enough. Therefore, students choose and practice specific methods for studying and learning. These methods may be precisely in line with the principles and techniques of learning, in which case it leads to higher academic achievement, or they may be contrary to the principles and methods of learning, in which case the academic achievement is not considerable and followed by despair, discouragement, and eventually academic failure. As previously said, we have to say whether these students are aware of self-regulated learning strategies or whether they are not aware of selfregulated learning strategies and how they are used. As we all know, self-regulated learning strategies allow students to interact more actively and efficiently with input data in learning situations. Therefore, this study examines the relationship between self-regulated learning strategies and students' academic performance in English courses.

\section{METHODOLOGY}

The research method was descriptive-correlational. The statistical population includes all students of Azad University, Gorgan branch in the period 2020-2021. 384 people were selected as the sample by convenience sampling and according to Morgan's table. The tests were explained in detail after preliminary explanations about the measurement tools and the test objective. Regarding ethical considerations, after obtaining the consent of individuals and giving the necessary information, they were assured that the information received is used solely in this research and is not abused. The following questionnaires were used to measure the research variables.

Zimmerman \& Pons Student Self-Regulated Learning Interview Schedule (SRLIS): This questionnaire was designed by Zimmerman and Pons in 1988 to assess selfregulated learning strategies. Zimmerman and Pons's (1988) 24-item SRLS questionnaire collected information on self-regulated learning strategies. The self-regulation 
questionnaire consists of 15 closed-ended questions. 4 options answered the questions (very low - low - high most of the time), and each question is given 1 to 4 points, respectively. 14 self-regulated learning strategies including self-assessment, organizing and transmitting, breaking down goals and planning, searching and recording information, and self-monitoring, organizing the environment, self-consequence, hierarchy and retention, peer help-seeking, teacher help-seeking, adults helpseeking, reviewing previous exams, reviewing notes and booklets, and reviewing textbooks are included in this questionnaire. The subject is asked to rate the above strategies in six learning situations with a four-point Likert scale from very low to high. In addition to the 14 strategies, question No. 15 is also used, which does not refer to a strategy, but allows the student to respond creatively. The range of points is from 15 to 60 . The questionnaire reliability was reported 0.87 in Kia and Abtin (2005) by internal consistency method and 0.89in Goldust (2009) using Cronbach's alpha. Learning motivation strategies Information was collected using MSLQ 44-question questionnaire in Eccles (1983). The reliability of this questionnaire was reported 0.83 in Weinstein and Mayer (1986). This questionnaire has been translated into Persian by Rafieian (2000) (quoted by Rabbani and Yousefi, 2013). Students' grade average in English courses in two semesters (first and second semesters of 2020) was considered academic performance. In this study, Cronbach's alpha test was used to determine the reliability of the test. For this purpose, 20 pre-test questionnaires were used, and then the confidence coefficient was calculated by Cronbach's alpha method, the data obtained from these questionnaires, and SPSS statistical software.
The value 0.75 was obtained for self-regulated learning strategies, addressing the optimal reliability of the measurement tool. Pearson correlation was used to analyze the data. In all analyzes, a significant level of $p$ $<0.05$ was considered.

\section{RESULTS}

The results of the Kolmogorov-Smirnov test showed that the distribution of data was normal ( $p>0.05)$. According to Table 1, the distribution of students by gender shows that 243 were male and 141 were female.

Table 1- Number and percentage of subjects by gender

\begin{tabular}{|l|l|l|}
\hline Gender & Frequency & $\begin{array}{l}\text { Frequency } \\
\text { percentage }\end{array}$ \\
\hline female & 243 & 63.0 \\
\hline Male & 141 & 37.0 \\
\hline Total & 384 & 100.0 \\
\hline
\end{tabular}

The correlation analysis results showed a significant positive relationship between self-regulated learning strategies and academic performance.

Table 2. Correlation between research variables

\begin{tabular}{|l|l|l|}
\hline \multicolumn{2}{|l|}{} & $\begin{array}{l}\text { Academic } \\
\text { performance }\end{array}$ \\
\hline $\begin{array}{l}\text { self-regulated } \\
\text { learning strategies }\end{array}$ & $\mathrm{r}$ & 45.0 \\
\cline { 2 - 3 } & $\mathrm{p}$ & 001.0 \\
\hline
\end{tabular}

Regression was used to predict academic performance from self-regulated learning strategies. Table 3 shows regression analysis results. According to this table, the regression model of academic performance based on selfregulated learning strategies is statistically significant $\left(R^{2}=\right.$ $0.062, \mathrm{p}<0.001, \mathrm{t}=4.54)$.

Table 3- Summary of regression model results

\begin{tabular}{|l|l|l|l|l|l|l|}
\hline Model - Predictive variables & $F$ & $R$ & $R^{2}$ & B (S.E.) & $\beta$ & $t$ \\
\hline Academic Performance & ${ }^{* *} 262.4$ & 257.0 & 062.0 & & & \\
\hline Constant & & & & ) $869.5(592.8$ & & 464.1 \\
\hline Self-regulated learning strategies & & & & ) $212.0(721.0$ & 246.0 & \\
\hline
\end{tabular}

\section{CONCLUSION}

This study examined the relationship between selfregulated learning strategies and students' academic performance in English courses. The results showed that there is a significant relationship between self-regulated learning strategies and students' academic performance. This result is in line with Rabbani et al. (2013), Saadatmand (2011), Goldust (2009), Shirdel (2012), Danila (2015), Amini (2008), Sobhaninejad (2006). For example, Danila (2015) showed that self-regulation skills strongly impact high school students' motivation, consistent with this study. Kimber (1995) showed no significant relationship between studying duration and learners' academic achievement, which is consistent with the present study. Self-regulation has practical consequences in the process of learning, education, and even life achievement. Adaptation and achievement in school require that students develop and reinforce their cognition, emotions, or behaviors by developing self-regulation or similar processes to achieve their goals. One research examined the relationship between goal orientation and motivational beliefs with self-regulated learning in students. The results showed that internal goal orientation and positive motivational patterns are associated with high cognitive and self-regulation strategies. In general, researchers have found that students perform significantly better who use metacognitive skills such as planning, control, monitoring, and evaluation in the learning process. In this regard, Sarason believes that the first step to achieving selfregulated learning and ultimately progress in learning, teaching, and promoting students' cognitive and metacognitive skills. Another point is that many students who can regulate and control their academic performance's cognitive and behavioral aspects have been successful as learners, and this shows that self-regulated learning is a predictor of academic performance. Self-regulated learning strategies help students' learning process and provide opportunities for them to actively manage processes such as goal setting, self-control, self-assessment, and selfmotivation. As learning goal orientation develops, they strengthen and facilitate learning motivation, which should be a priority for planners and those involved in education. Self-regulated learning methods are active and conscious use of appropriate learning strategies that include complex 
activities to achieve learning goals. Those involved in education always try to find the ideal conditions for learning and teaching, thereby facilitating and improving the learning process. On the other hand, cognitive strategies are learning tools and any behavior, thought, or action that the learner uses while learning, organizing, and storing knowledge and skills (Alborzi, 2008, Salehian and Ghadiri, 2018, bani Asadi and Salehian, 2021). Another point is that students can improve their academic achievement by better understanding the self-regulated learning process. Many students experience frustration and academic failure due to a lack of learning strategies skills; on the other hand, learning strategies are used to solve academic problems and help students develop the skills they need during their studies. Identifying and strengthening these strategies helps people to discover and strengthen their abilities and complete their education successfully.

\section{REFERENCES}

1. Alborzi, Seif. (2009). "and examination and comparison of motivational beliefs and self-regulated learning strategies among middle school male and female students of Shiraz Talent Center." Journal of Social Sciences and Humanities, Shiraz University, 15 (1), 34-57

2. Amini, Mohammad (2008). The Relationship between Selfregulated learning Strategies and Motivational Beliefs with Students' Academic Achievement, New Educational Thoughts, No. 17, 123-136.

3. BaniAsadi, T., Salehian, M.H. (2021). The Effect of Psychological Well-being on Athletic Performance of Professional Athletes, Pakistan Journal of medical health and Sciences, 15(5), 1680-1683

4. Rabbani, Zeinab., Farideh, Yousefi. (2013). The relationship between motivational beliefs and academic achievement with the mediating role of various goal orientations and selfregulated learning strategies. Journal of Psychology, Eighteenth Year, No. 3, pp. 17, 24-36
5. Saadatmand, Zohra; Farzad Saadatmand and Mojtaba Bahrami, 2011, The Relationship between Social Growth and Academic Achievement of High School Students in Isfahan, National Conference on Pathology of Youth Issues, Falavarjan, Islamic Azad University, Falavarjan Branch

6. Salehian, M.H., Ghadiri, S. (2018). Anticipation of Emotion Regulation and Psychological Well-being on Athletic Performance of Professional and Semi-professional Athletes, Sport Psychology Studies, 8 (29), 151-17.

7. Sobhaninejad, Mehdi Vahed, Abedi (2006). Investigating the relationship between self-regulated learning strategies and motivation of students' academic achievement with their academic performance in a mathematics course in Isfahan, Journal of Psychology, University of Tabriz, No. 1. 54-68

8. Shirdel, Khair Al-Nisa. (2012). The relationship between selfregulated learning strategies and achievement motivation with the academic performance of high school students in district 1, Sari. Master Thesis in Islamic Azad University, Sari Branch.

9. Kajbaf, Mohammad Baqir (2003). Relationship between motivational beliefs and self-regulated learning strategies with high school student's academic performance. Cognitive Science Quarterly, Volume 5, Number 1, 74-83

10. Goldust, Asghar. (2009). Relationship between selfregulated learning strategies and learning motivation strategies with students' academic performance of Islamic Azad University, Ardabil Branch Knowledge and Research in Educational Sciences Curriculum Planning, Islamic Azad University, Khorasgan Branch (Isfahan) No. 23, Fall 2009, pp. 85-100.

11. Behrouzi M, Amouzgar A, Alipour Y. [A Pathological Study on English Course Curriculums: High School Instructors' and Students' Insights Scrutinized]. The new approaches in educational management 2014; 5 (18): 125-142

12. Daniela $P$. The relationship between self- regulation, motivation and performance at secondary school students. Social and Behavioral Sciences 2015; 19 (1): 2549-2553

13. Kember D, Jamieson QW, Pomfret M, Wong TT., Learning Approaches, Study Time and Academic Performance, Higher Education 1995; 29 (3): 392-343 